\title{
Laboratory Bioassay for the Efficacy of Coriander and Rosemary Extracted Essential Oils on the Citrus Brown Mite, Eutetranychus orientalis (Actinidida: Tetranychidae)
}

\author{
Ashraf S. Elhalawany, Aziza, M. Abou-Zaid and Ahmad I. Amer \\ Plant Protection Research Institute, Agricultural Research Center, Dokki, Giza, Egypt, drashrafsaid2@gmail.com.
}

\begin{abstract}
The objective of this study was to evaluate the toxicity and repellency effect of Rosemary, Rosmarinus officinalis L. (herb) and Coriander, Coriandrum sativum L. (fruits) essential oils against Eutetranychus orientalis (Klein). Essential oils were extracted using aqueous extract. The chemical composition of the extracted essential oils was characterized by GC. The main components were Linalool and camphor, respectively. Concentrations of 0.5, 1, 2, 3 and $4 \%$ were tested. Results indicated significant differences in efficiency of the tested essential oils on the developmental stages of $E$. orientalis. Coriander essential oil was more toxic for controlling different stages of E. orientalis than Rosemary ones. For eggs, $\mathrm{LC}_{50}$ and $\mathrm{LC}_{90}$ were $4.82 \%$, while for Rosemary; it was 1.49 and $7.94 \%$, respectively after 7 days. Relative values after 3 days for larval stage were: $0.160,1.340,0.280$ and 20.080 respectively. For nymphal stage relative values were: $0.21,1.52,0.20$ and 4.37 . For adult stage relative values were: $0.77,4.09,0.37$ and 6.10 , respectively. It was concluded that Coriander essential oil was more potent to E. orientalis than Rosemary ones. Repellency of different tested concentrations for adult females indicated significant effects of the two oils, concentration and time. Coriander was significantly more repellant than Rosemary. Repellency significantly increased with concentration increased and decreased by time increase. It was concluded that Coriander and Rosemary essential oils could potentially used for the management of $E$. orientalis. More efforts are suggested to evaluate these oils and their components as natural ones for controlling this pest.
\end{abstract}

Key words: Essential oils, Eutetranychus orientalis, Rosemary, Coriander, Toxicity, Repellency.

\section{INTRODUCTION}

The citrus brown mite, Eutetranychus orientalis (Klein) is an important pest of citrus being a persistent pest in Upper Egypt. It also infests a several crops including apple, peach, grape, guava, papaya, date palm, grapevines, quince, cotton, eggplant, castor bean, cucurbits and a variety of ornamentals being reported on 228 host plants of 58 families worldwide. The mites colonize the upper side of leaves where it feed, and their damage develops as yellow-grey stippled spots which cause leaf wilting and drop (Zaher, 1984; Elhalawany, 2001).

As results of the continuous application of pesticides, spider mites became resistant to miticides. Food contamination, mammalian toxicity and pollution of the environment are other problems to be uncounted. Thus approach in pest control such as natural plant products must receive considerable attention (El-Halawany et al. 1989).

Studies on plant extracts having acaricidal influences on the citrus brown mite E. orientalis are few. Among these are the essential oils of Majorana hortensis Moench, Rosmarinus officinalis L., Ocimum basilicum L., Lavandula officinalis Chaix, Francoeria crispa (Forssk), Orange Peel, Lemon grass (El-Safty, 1993; Amer, et al., 1993; Amer et al., 2001and Abdel-Khalek et al., 2010). Elhalawany and Dewidar (2017) studied the effect of seven oils of the plants Lemon grass, Spearmint, Rosemary, Marjoram, fennel, Coriander and Chamomile on Tetranychus urticae Koch, suggesting that the essential oils of the seven plants have potential to be used for management of $T$. urticae. The aim of this work was to study the toxicity and repellency of Coriander and Rosemary oils extracts on E. orientalis and the potential of using them as an alternative to pesticides.

\section{MATERIALS AND METHODS}

\section{Plant material, extraction and analysis of volatile oils:}

Two essential oils extracted from Rosemary herb and Coriander fruits were tested. Plant materials were obtained from the medicinal and aromatic plants Department Farm, Horticulture Research Institute, Agriculture Research Center, El-Qanater El-Khayreya, Qalyubia, Egypt.

The air dried plants were hydro distilled in a Clevenger-type apparatus for $4 \mathrm{~h}$, according to the procedure described in the Egyptian Pharmacopeia (2005) to determine the volatile oil percentage (volume/weight). The obtained oils were dehydrated by filtration through anhydrous sodium sulfate and kept in a refrigerator in dark bottles for GC analysis. The Extraction of volatile oils and its components were carried out at Medicinal and Aromatic Plants Research Department Laboratory, Horticulture Research Institute, Agriculture Research Center, Giza, Egypt.

\section{Gas chromatography analysis (GC):}

The GC analysis of the volatile oil samples was carried out using gas chromatography instrument at 
the Medicinal and Aromatic plants Dept. Laboratory, Horticulture Research Institute. DsChrom 6200 Gas Chromatograph was equipped with a flame ionization detector, Column: BPX-5, 5\% phenyl (equiv.) polysillphenylene-siloxane $30 \quad \mathrm{~m} \quad \mathrm{x} \quad 0.25 \quad \mathrm{~mm}$ ID x $0.25 \mu \mathrm{m}$ film. Sample size: $1 \mu$, Temperature program ramp increased with a rate of $10^{\circ} \mathrm{C} / \mathrm{min}$ from 70 to $200{ }^{\circ} \mathrm{C}$, Detector temperatures (FID): $280^{\circ} \mathrm{C}$. Carrier gas: nitrogen. Flow rate: $\mathrm{N}_{2} 30 \mathrm{ml} / \mathrm{min}$; H2 $30 \mathrm{ml} / \mathrm{min}$; air $300 \mathrm{ml} / \mathrm{min}$. Main compounds of the volatile oils were identified by matching their retention times with those of the authentic samples injected under the same conditions. The relative percentage of each compound was calculated from the area of the peak corresponding to each compound.

\section{Preparation of the emulsions:}

Emulsions of the two essential oils were prepared for different concentrations by mixing of Triton-x 100 with oils and completed with distilled water in exact volume.

\section{Stock culture of $E$. orientalis}

Culture of $E$. orientalis was collected from infested castor bean plants in Qaha Agriculture Research Station (ARC), Qualyubia governorate, Egypt in May 2018. Seeds of castor bean plants were planted in pots containing soil and leaf compost. After suitable growth, plants were infected with $E$. orientalis. The stock culture was maintained in small greenhouse $5 \times 5 \mathrm{~m}^{2}$. After several generations, mites from the stock colony were used for the tests.

\section{Experimental design}

An experimental foam dish $(15 \times 20 \mathrm{~cm})$ with a castor bean leaf disc (3 $\mathrm{cm}$ in diameter) kept upside down on moistened cotton pads resting on sponge. Water was replaced, as required to prevent the mites from escaping and to keep the culture healthy. A total of 30 experimental foam dishes were divided into two treatments and a control, with ten replicates in each treatment.

\section{Treatment of $E$. orientalis eggs}

Leaf discs of castor bean leaves were used as substrate to oviposition. Ten leaf discs were used for each treatment and ten mite females were transferred to each disc and left $24 \mathrm{~h}$ to lay eggs, then females were removed. Each test contained 5 concentrations and each concentration had 10 replicate (10 eggs/ replicate). Eggs were sprayed by a glass atomizer with each concentration for every essential oil and other with distilled water (control). Eggs were maintained at temperature $28^{\circ} \mathrm{C}$ conditions for 7 days till hatching. The numbers of hatched and non hatched eggs were recorded.

\section{Treatment of E. orientalis larvae, nymphs and} adult females

Ten individuals of larvae, nymphs and adult females of $E$. orientalis were transferred to the lower surface of each castor bean leaf disc. Each test contained 5 concentrations and each concentration had 10 replicates (10 individuals/replicate) treated previously, using a fine camel hairbrush. Leaf discs were treated with one of previous treatments. In each test, a control was included using distilled water and two drops of Triton X-100. Each treatment was replicated six times. Mortality was recorded after 24, 48 and $72 \mathrm{~h}$ post treatments under a binocular microscope. Mites were considered to be dead if their bodies or appendages did not move when prodded with fine camel hairbrush (Elhalawany and Dewidar, 2017).

\section{Repellency test procedures for $E$. orientalis females:}

The repellency tests were performed according to method described by Amer et al. 2011. Castor bean leaf discs $(5 \mathrm{~cm}$ diam.) were prepared with surfaces upside-down in Petri- dish, lined with moist cotton wool. Half of each disc was dipped with five of aqueous concentrations of each essential oil for 5 seconds and left to dry, while the other half left untreated as control. Ten females were put on the middle of the leaf disk using a fine tipped paint brush. The number of mites on treated or control half was recorded after 24 and 48-hr. Ten replicate leaf discs were used per concentration of each essential oil. Each treatment was repeated for three times. The repellency index was calculated by $\mathrm{RI}=(\mathrm{C}-\mathrm{T} / \mathrm{C}+\mathrm{T})$ $\times 100$ (Pascual-Villalobos and Robledo, 1998). In this formula RI stands for repellency index, $\mathrm{T}$ is the number of mites in treatment and $\mathrm{C}$ is the number of mites in the control.

\section{Statistical analysis}

Data obtained from each dose-response bioassay were subjected to probit analysis (Finney, 1971) to estimate LC50 and $\mathrm{LC}_{90}$ values using Ldp line software http://www.ehabsoft.com/ldpline/. Repellency data were analyzed using analysis of variance (ANOVA) and Least Significant Difference Test (LSD) in SAS Program version 9.1.3 (SAS Institute, 2003).

\section{RESULTS AND DISCUSSION}

\author{
Chemical compositions of extracted essential \\ oils: \\ The obtained results are illustrated in Figs \\ (1\&2). They present the gas chromatography \\ analysis GC-MS for two essential oils. Gas \\ chromatography analysis for volatile oils showed \\ that, the Coriander seed oil contains 12 compounds \\ of which the major
}




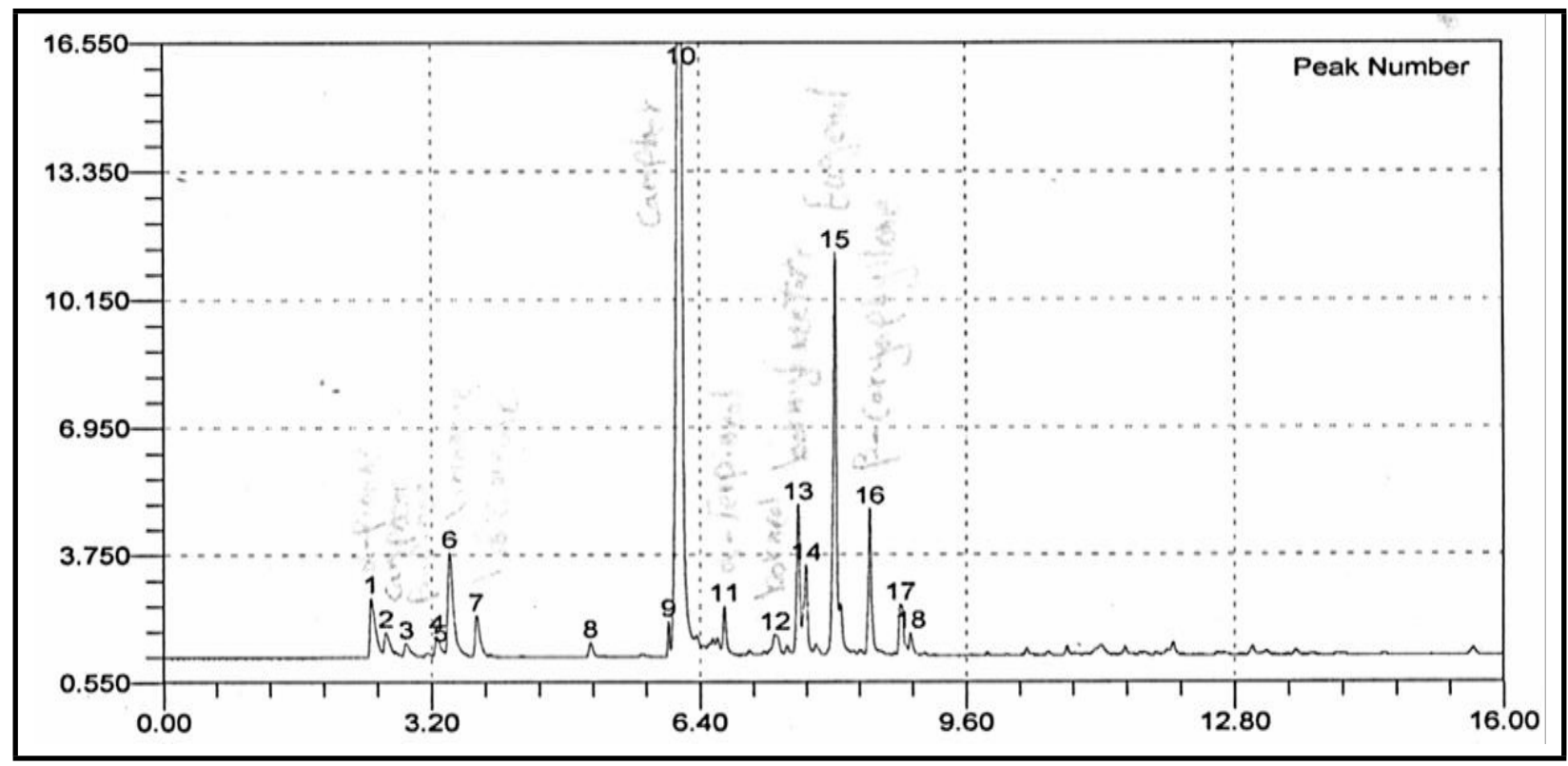

Fig. (1): GC analysis chromatogram for Rosemary volatile oil.

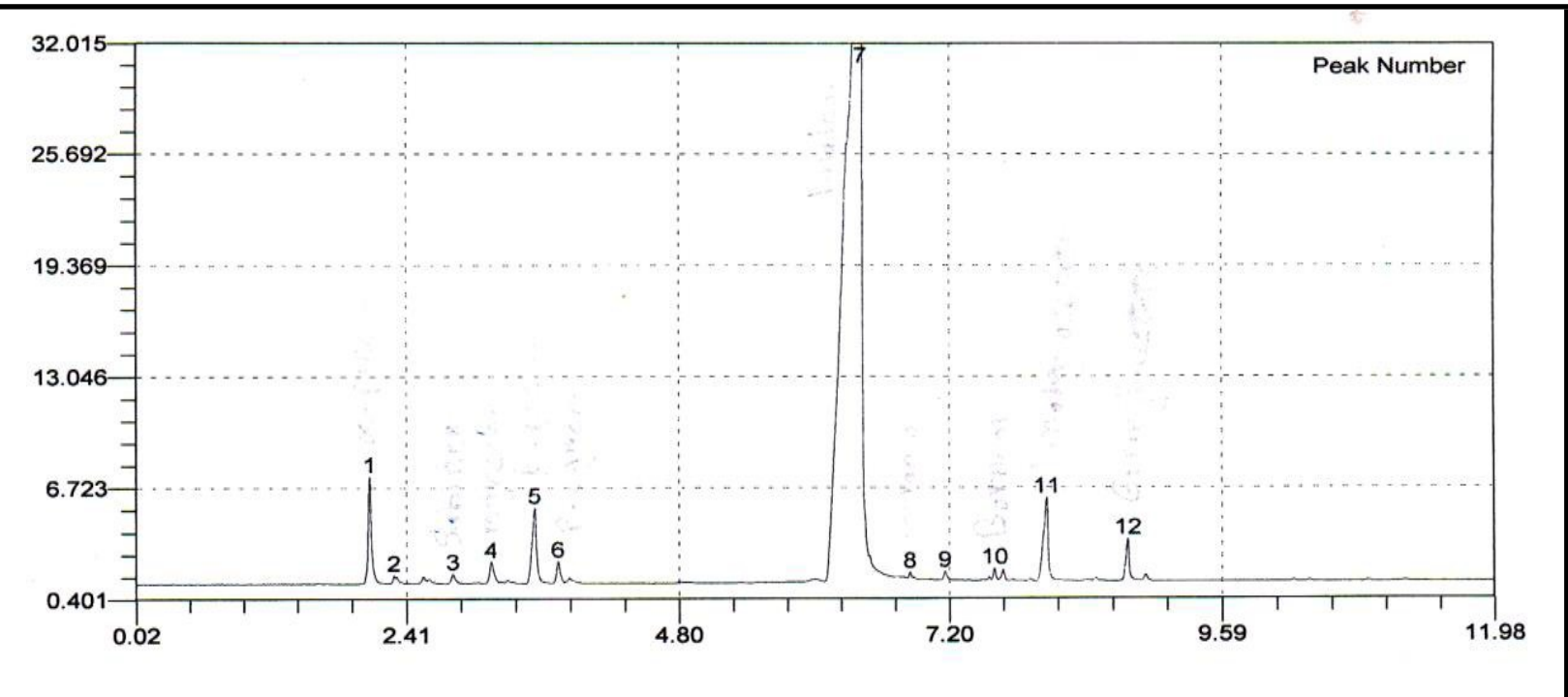

Fig. (2): GC analysis chromatogram for Coriander volatile oil.

compounds were linalool (85.60\%), $\alpha$-Pinene (2.44\%), $\quad \beta$-Pinene (2.40\%) and Linalyl acetate (3.23\%). Whereas Rosemary volatile oils contained 18 compounds mostly of camphor (54.36\%), Eugenol (14.17\%), $\alpha$-Pinene (3.05\%), Limonene (5.10\%), Bornyl acetate (4.66\%) and $\beta$-caryophyllene (4.30\%). Comparable results were obtained by Bhuiyan et al. (2009) who indicated that the Coriander seed oil contained 53 compounds where the major compounds were linalool (37.7\%) and geranyl acetate (17.6\%). Linalool was reported as major constituents of Coriander seeds (Coleman and Lawrence, 1992). Other constituents were 1,8-cineol (33.08-37.75\%), camphor (13.55-18.13\%), a-pinene (8.58-9.32\%), aterpineole (6.79-8.17\%), camphene (5.07-5.58\%), borneol (4.08-5.48\%), limonene (3.19-3.04\%) and p-cymene (2.42-3.11\%). Yildırım (2018) indicated that the Rosemary containd 27 components, the major components were 1.8 cineole (41.25\%-45.96\%), isoborneol (11.96\%-14.89\%), $\alpha$-pinene (9.28\%$11.22 \%)$ and $\alpha$-terpineol (4.65\%-8.41\%). Camphene (3.29\%-3.51\%), Limonene (2.89\%-3.61\%), pcymene (3.64\%-4.26\%) and Bornyl acetate (2.02\%$3.13 \%$ ) found as moderately high compounds.

\section{Toxicity of the two essential oils for $E$. orientalis eggs}

Obtained results are presented in Table (1). The two tested essential oils had toxic effects on $E$. orientalis eggs hatchability. Coriander oil was the more potent $\left(\mathrm{LC}_{50}=1.26\right.$ and $\left.\mathrm{LC}_{90}=4.82\right)$, while Rosemary oil was the less toxic $\left(\mathrm{LC}_{50}=1.49\right.$ and $\left.\mathrm{LC}_{90}=7.94\right)$. The slopes for Coriander and Rosemary were 2.20 and 1.76, respectively. Elhalawany and Dewidar (2017) indicated that $\mathrm{LC}_{50}$ values for eggs of T. urticae were 1.54, 6.44, 0.96, 1.72, 1.30, 14.67 and 
Table (1). Toxicity effect of two essential oils against $E$. orientalis stages after 24,48 and $72 \mathrm{~h}$

\begin{tabular}{|c|c|c|c|c|c|c|c|c|}
\hline Stage & Essential oils & Time (h) & $\mathrm{LC}_{50}$ & $\mathrm{LC}_{90}$ & Lower limit \% & Upper limit \% & Slope & Toxicity index \\
\hline \multirow{2}{*}{ Egg } & Coriander & 7 days & 1.26 & 4.82 & 3.93 & 6.37 & 2.2 & 100.00 \\
\hline & Rosemary & 7 days & 1.49 & 7.94 & 5.86 & 12.4 & 1.76 & 60.71 \\
\hline \multirow{6}{*}{ Larva } & \multirow{3}{*}{ Coriander } & 24 & 0.20 & 1.51 & 1.88 & 2.04 & 1.47 & 88.68 \\
\hline & & 48 & 0.18 & 2.58 & 1.88 & 4.40 & 1.21 & 51.87 \\
\hline & & 72 & 0.16 & 1.34 & 1.03 & 1.80 & 1.40 & 100.00 \\
\hline & \multirow{3}{*}{ Rosemary } & 24 & 1.07 & 39.7 & 14.91 & 409.76 & 0.81 & 3.37 \\
\hline & & 48 & 0.50 & 41.02 & 13.03 & 1311.8 & 0.67 & 3.26 \\
\hline & & 72 & 0.28 & 20.08 & 8.01 & 294.13 & 0.69 & 6.67 \\
\hline \multirow{6}{*}{ Nymph } & \multirow{3}{*}{ Coriander } & 24 & 0.36 & 2.97 & 2.28 & 4.47 & 1.40 & 51.26 \\
\hline & & 48 & 0.25 & 2.17 & 1.71 & 2.99 & 1.38 & 70.27 \\
\hline & & 72 & 0.21 & 1.52 & 1.20 & 2.05 & 1.50 & 100.00 \\
\hline & \multirow{3}{*}{ Rosemary } & 24 & 0.48 & 9.64 & 5.6 & 28.72 & 0.99 & 15.81 \\
\hline & & 48 & 0.27 & 5.91 & 3.59 & 17.97 & 0.95 & 25.76 \\
\hline & & 72 & 0.20 & 4.37 & 2.88 & 10.24 & 0.95 & 34.84 \\
\hline \multirow{6}{*}{ Adult } & \multirow{3}{*}{ Coriander } & 24 & 1.27 & 6.13 & 4.73 & 8.88 & 1.87 & 66.69 \\
\hline & & 48 & 0.91 & 4.52 & 3.57 & 6.31 & 1.85 & 90.49 \\
\hline & & 72 & 0.77 & 4.09 & 3.22 & 5.75 & 1.70 & 100.00 \\
\hline & \multirow{3}{*}{ Rosemary } & 24 & 0.94 & 16.11 & 8.67 & 53.37 & 1.04 & 25.40 \\
\hline & & 48 & 0.56 & 13.4 & 7.07 & 51.43 & 0.93 & 30.54 \\
\hline & & 72 & 0.37 & 6.1 & 3.94 & 13.98 & 1.05 & 67.08 \\
\hline
\end{tabular}

Toxicity index was calculated with respect to the most effective compound LC90

Table (2) Repellency effects of two plants essential oils on E. orientalis females

\begin{tabular}{ccccc}
\hline \multirow{2}{*}{ Concentration \% } & \multicolumn{2}{c}{$24 \mathrm{~h}$} & \multicolumn{2}{c}{$48 \mathrm{~h}$} \\
\cline { 2 - 5 } & Coriander & Rosemary & Coriander & Rosemary \\
\hline 0.5 & $44.0 \pm 12.6$ & $38.0 \pm 17.5$ & $32.0 \pm 19.3$ & $26.0 \pm 13.5$ \\
\hline 1 & $54.0 \pm 13.5$ & $42.0 \pm 14.8$ & $42.0 \pm 11.4$ & $30.0 \pm 19.4$ \\
\hline 2 & $72.0 \pm 14.0$ & $52.0 \pm 16.9$ & $52.0 \pm 21.5$ & $44.0 \pm 22.7$ \\
\hline 3 & $84.0 \pm 12.6$ & $64.3 \pm 18.4$ & $70.3 \pm 23.4$ & $54.0 \pm 19.0$ \\
\hline 4 & $92.0 \pm 10.3$ & $70.0 \pm 19.4$ & $82.2 \pm 14.2$ & $60.0 \pm 23.1$ \\
\hline
\end{tabular}

Table (3) Factorial analysis for repellency effects on E. orientalis females

\begin{tabular}{|c|c|c|}
\hline Factor & Level & Mean \\
\hline \multirow{2}{*}{ Extracted oil } & Coriander & $62.45^{\mathrm{a}}$ \\
\hline & Rosemary & $48.03^{b}$ \\
\hline F value & & 68.95 \\
\hline $\mathrm{P}$ value & & 0.0001 \\
\hline LSD & & 3.752 \\
\hline \multirow{2}{*}{ Time (hours) } & 24 & $61.23^{\mathrm{a}}$ \\
\hline & 48 & $49.25^{b}$ \\
\hline F value & & 47.59 \\
\hline P VALUE & & 0.0001 \\
\hline LSD & & 3.752 \\
\hline \multirow{5}{*}{ Concentration (\%) } & 0.5 & $35^{\mathrm{e}}$ \\
\hline & 1 & $42^{\mathrm{d}}$ \\
\hline & 2 & $55^{c}$ \\
\hline & 3 & $68.15^{\mathrm{b}}$ \\
\hline & 4 & $76.05^{\mathrm{a}}$ \\
\hline F value & & 78.57 \\
\hline $\mathrm{P}$ value & & 0.0001 \\
\hline LSD & & 5.932 \\
\hline
\end{tabular}

Different letters on the same column indicate significant difference ( $\mathrm{P} \leq 0.05)$. 
0.95\% for lemon grass, spearmint, Rosemary, marjoram, fennel, Coriander and chamomile essential oils, respectively.

\section{Toxicity effect of two essential oils against $E$. orientalis different stages \\ Larval stage:}

The for mentioned results in (Table 1) clarified that, the corresponding $\mathrm{LC}_{50}$ values of Coriander and Rosemary against $E$. orientalis larvae after $24 \mathrm{~h}$ of treatment were 0.20 and $1.07 \%$, and the corresponding $\mathrm{LC}_{90}$ values were 1.51 and $39.70 \%$, respectively. While the corresponding $\mathrm{LC}_{50}$ values after $48 \mathrm{~h}$ of treatment against the larvae of $E$. orientalis were 0.18 and $0.50 \%$, and the consequent $\mathrm{LC}_{90}$ values were 2.58 and $41.02 \%$, respectively. Coriander recorded the highest slope value after 24 and $48 \mathrm{~h} 1.47 \& 1.21$, respectively; whereas the lowest slope values were $0.81 \& 0.67$ for Rosemary oil after 24 and $48 \mathrm{~h}$, respectively. On the other hand, the corresponding $\mathrm{LC}_{50}$ values after $72 \mathrm{~h}$ for larvae were 0.16 and $0.28 \%$ and the consequent $\mathrm{LC}_{90}$ values were 1.34 and $20.08 \%$, respectively. The slope values of regression line were 1.4 and 0.69 for Coriander and Rosemary after $72 \mathrm{~h}$ for larvae, respectively. At the level $\mathrm{LC}_{50}$ the relative potency levels expressed as number of folds indicated that Rosemary 20.08 times as toxic as Coriander oil after $72 \mathrm{~h}$. It was statistically determined that the effect of the two essential oils toxicity to E. orientalis larvae increased with an increase in concentration.

\section{Nymphal stage:}

Applying the same tests (Table 1) indicated that significant differences occurred between the two essential oils. Coriander extracted oil was more toxic than Rosemary ones on nymphal stages of $E$. orientalis. The corresponding $\mathrm{LC}_{50}$ values of Coriander and Rosemary against the nymphal stages of E. orientalis were $0.36 \& 0.48,0.25 \& 0.27$, and $0.21 \& 0.2 \%$ after 24,48 and $72 \mathrm{~h}$, respectively; whereas the $\mathrm{LC}_{90}$ values were $2.97 \& 9.64,2.17 \& 5.91$ and $1.52 \& 4.37 \%$ at the same times, respectively.

\section{Adult female:}

As presented in Table (1) $\mathrm{LC}_{50}$ values increased as time increased after application, the Ldp-lines of toxicity effects of two essential oils on adult females of $E$. orientalis. When compare between the effects of essential oils on mortality percentage of $E$. orientalis females after $72 \mathrm{~h}$ from treatment it can be conducted that Rosemary was more toxic with $\mathrm{LC}_{50}$ value $0.37 \%$; $\mathrm{LC}_{90}$ value $6.1 \%$ and the slope values gave 1.05 , whereas Coriander was less toxic to adult of females of E. orientalis with $\mathrm{LC}_{50}$ values $0.77 \%$; $\mathrm{LC}_{90}$ values $4.09 \%$ and the slope values gave 1.7 .
The obtained results are in harmony with that detected by Iskander (1993) who determined that LC $_{50}$ were 250.95 and 406.44 ppm, while LC 90 values were 564.93 and 696.31 ppm for Duranta and Lantana for Eutetranychus anneckei Meyer (E. orientalis). Elhalawany and Dewidar (2017) found that LC 50 values for the $T$. urticae adult females after $72 \mathrm{~h}$ were $1.28,0.85,0.53,1.61,0.44,3.11$ and $0.46 \%$ for Lemon grass, Spearmint, Rosemary, Marjoram, Fennel, Coriander and Chamomile, respectively.

\section{Repellency effects of two plants essential oils on $E$. orientalis females.}

The repellent effects of different concentrations of Coriander and Rosemary oils on E. orientalis adults are presented in Table (2). Factorial analyses of these results are presented in Table (3). Repellency of different tested concentrations for adult females indicated significant effects of the two oils, concentration and time. Coriander was repellant than Rosemary. Repellency increased with concentration increased and decreased by time increase.

The obtained results are in agreement with that recorded by Schauer and Schmutterer (1981) who indicated that aqueous extracts and high concentrations (10, 5 and 2.5\%) of methanolic extracts of Neem seed were strongly repellent to $T$. urticae adult mites. The application of the 10\% methanolic extract to eggs resulted in high mortality of larvae and nymphs. Mansour et al. (1986) found that bean leaf discs sprayed with concentrations of the acetonic solutions of the Rosemary oil from 0.1 to $2 \%$ caused mortality and induced repellency to $T$. cinnabarinus (Boisd) within $48 \mathrm{~h}$ of placing adult females on the discs and consequently egg-laying was reduced. El-Halawany and Sawires (1988) tested six essential volatile oils against $T$. urticae, whereas repellency percentage ranged between $70 \%$ and $85 \%$ for Marjoram treatment. Both Rosemary and Sweet Marjoram oils gave $100 \%$ repellency to T. urticae at $10 \%$ level of concentration (Sawires et al., 1988). Amer et al., (1993), indicated that the Orange Peel oil showed a remarkable deterrent effect with $E$. orientalis than T. urticae. El-Safty (1993) showed that at concentration $10 \%$ the repellency percentages were 32.35, 30.56 and $52.77 \%$ after $72 \mathrm{hr}$. of adult $E$. orientalis. Hori and Komatsu (1997) found that Rosemary volatile oil and its principle component 1,8-cineole was repellent against Neotoxoptera formosana. Amer et al. (2001) indicated that Rosemary oil proved to be completely deterrent for $E$. orientalis even after $72 \mathrm{~h}$.

It was concluded that Coriander and Rosemary essential oils and their two major constituents 
Linalool and camphor could potentially use for the management of $E$. orientalis. More efforts are suggested to evaluate these components as natural ones for controlling this pest.

\section{ACKNOWLEDGMENTS}

The authors thank Dr. Ahmed Dewidar (Medicinal and Aromatic Plants Department, HRI, ARC, Egypt) for his assistance in extraction and analysis of essential oil.

\section{REFERENCES}

Abdel-Khalek, A.A.; Amer, S.A. and Momen, F.M. 2010. Repellency and toxicity effect of plant extract from Francoeria crispa (Forssk) against Eutetranychus orientalis (Klein) (Acari: Tetranychidae). J. Plant Protec. Patho., 1: 9 -19.

Amer, S.A.; Abou-Awad, B. A. and El- Banhawy, E. M. 1993. Toxicity of the orange peel and lemon grass oils to the spider mites Tetranychus urticae and Eutetranychus orientalis with effects on the development and reproduction (Acari: Tetranychidae). Afr. J. Agric. Sci. 20: 95-102.

Amer, S.A.; Refaat, A. and Momen, F.M. 2001. Repellent and oviposition-deterring activity of Rosemary and sweet marjoram on the spider mites Tetranychus urticae and Eutetranychus orientalis (Acari: Tetranychidae). Acta Phytopath. et Entomol. Hung. 36: 155-164.

Amer, S.A.; Mohamed, F.M.; Kamel, A.M.; Darwish, Z.E.; Hussein, H.E and El-Desouky, M.E. 2011. Acaricidal activity of some Lamiaceae plant essential oils against Tetranychus urticae Koch. Acarines, 5:11-17.

Bhuiyan, M.N., Jaripa Begum, J. and Sultana, M. 2009. Chemical composition of leaf and seed essential oil of Coriandrum sativum L. from Bangladesh. Bangladesh J. Pharmacol, 4: 150153.

Coleman, W.M. and Lawrence, B.M. 1992. Comparative automated static and dynamic quantitative headspace analysis of Coriander oil. J. Chromatogr Sci. 30: 396-98.

Egyptian Pharmacopeia 2005. Central Administration of Pharma ceutical Affairs (CAPA), Cairo, Egypt, Ministry of Health and Population, $4^{\text {th }}$ ed, 31-33.

Elhalawany, A.S. 2001. Studies on some mite species infesting some fruit trees. M.Sc. Thesis Fac. Agric., Moshtohor, Benha Unvi, 164 pp.

Elhalawany, A.S. and Dewidar, A.A. 2017. Efficiency of some plant essential oils against the two-spotted spider mite, Tetranychus urticae Koch and the two predatory mites Phytoseiulus persimilis (A.-H.), and Neoseiulus californicus (McGregor). Egypt. Acad. J. Biolog. Sci., 10(7): 135-147.

El-Halawany, M.E. and Sawires, Z.R. 1988. Biological and toxicological studies of certain plant extracts on Tetranychus urticae Koch. Bull. Zool. Soc., Egypt, 36: 37-41.

El-Halawany, M.S.; Ibrahim, G.A.; Abo-El-Ghar, G. and Nassar, M.E. 1989. Repellency and toxic effects of certain plant extracts on Tetranychus arabicus Attiah (Acarina: Tetranychidae). Agric. Res. Rev., 67(1): 69-74.

El-Safty, A.F. 1993. Toxicological and biological studies on citrus brown mite Eutetranychus orientalis (Kelin). M.Sc. Thesis Fac. Agric., Cairo Univ.120 pp.

Finney, D.J. 1971. Probit Analysis. $3^{\text {rd }}$ Edition, Cambridge University Press, London, 333pp.

Hori, M. and Komatsu, H. 1997. Repellency of Rosemary oil and its components against the onion aphid, Neotoxoptera formosana (Takahashi) (Homoptera: Aphididae). Appl. Entomol. Zool., 32: 303-310.

Iskandar, A.K. 1993. Ecological and biological studies on some tetranychoid mites. Ph. D. Thesis. Fac. Agric., Mansoura Univ., 109pp.

Mansour, F.; Ravid, U. and Putievsky, E 1986. Studies of the effects of essential oils isolated from 14 species of labiatae on the carmine spider mite, Tetranychus cinnabarinus. Phytoparasitica 14:137-142.

Pascual-Villalobos, M. J. and Robledo, A. 1998. Anti-insect activity of plant extracts from the wild flora in Southern Spain. Biochem.-Syst. Ecology, 27: 1-10.

SAS Institute. 2003. SAS Statistics and Graphics Guide, Release 9.1.3. SAS Institute, Cary, North Carolina, 275l3, USA.

Sawires, Z.R.; El-Halawany, M. and Nassar, M. 1988. Response of Tetranychus urticae Koch to some naturally active products. Bull. Zool. Soc., Egypt. 36: 42-45.

Schauer, M. and Schmutterer, H. 1981. Effects of Neem kernel extracts on the two-spotted spider mite, Tetranychus urticae. Prec. $1^{\text {st }}$ Int. Neem Conf. (Rottach-Egern, 1980). pp. 259-266.

Yildırım, E.D. 2018. The effect of seasonal variation on Rosmarinus officinalis (L.) essential oil composition. Inte. J. Agric. Wildlife Sci., 4: 33 38.

Zaher, M.A. 1984. Survey and ecological studies on phytophagous, predaceous and soil mites in Egypt. I: Phytophagous mites in Egypt (Nile valley and Delta). PI 480 Programme. USA Project No. EG. ARS, 30. Grant. No, FG, Eg., 228 pp. 